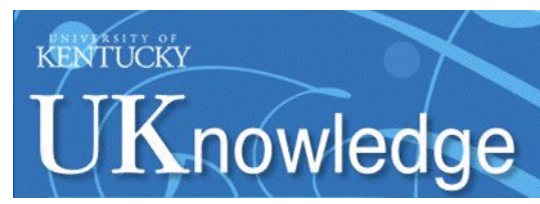

University of Kentucky

UKnowledge

Nursing Faculty Publications

College of Nursing

10-2015

\title{
Protecting Ourselves from Harm: Voices of Aging Farmers
}

Deborah B. Reed

University of Kentucky, dbreed01@uky.edu

Deborah T. Claunch

University of Kentucky, dtclau2@uky.edu

Follow this and additional works at: https://uknowledge.uky.edu/nursing_facpub

Part of the Nursing Commons

Right click to open a feedback form in a new tab to let us know how this document benefits you.

\section{Repository Citation}

Reed, Deborah B. and Claunch, Deborah T., "Protecting Ourselves from Harm: Voices of Aging Farmers" (2015). Nursing Faculty Publications. 26.

https://uknowledge.uky.edu/nursing_facpub/26

This Article is brought to you for free and open access by the College of Nursing at UKnowledge. It has been accepted for inclusion in Nursing Faculty Publications by an authorized administrator of UKnowledge. For more information, please contact UKnowledge@lsv.uky.edu. 


\section{Protecting Ourselves from Harm: Voices of Aging Farmers}

\section{Digital Object Identifier (DOI)}

http://dx.doi.org/10.13031/jash.21.11100

\section{Notes/Citation Information}

Published in Journal of Agricultural Safety and Health, v. 21, no. 4, p. 269-279.

(C) 2015 ASABE

The copyright holders have granted the permission for posting the article here. 


\title{
Protecting Ourselves from Harm: Voices of Aging Farmers
}

\author{
D. B. Reed, D. T. Claunch
}

ABSTRACT. Senior farmers suffer the highest fatality risk of any age group in agriculture. The purpose of this exploratory study was to develop a "voice" for senior farmers by examining aging farmers' and their families' perspectives of farm work, associated injury risks, and methods to decrease those risks. Focus groups and personal interviews were used to collect data from 81 participants across seven U.S. states. The findings reflect the collective and verified voice of the study group. The Health Belief Model was applied and revealed differences between farmers and their family members; however, the need and desire to continue self-directed work was ubiquitous. Seniors reported external risks, while family members were more likely to name risks associated with the health of the senior farmer. Both groups cited stress as an injury risk. Posing risk to others was the trigger point for senior farmers to make behavior changes. Family members reported uneasiness in initiating safety conversations. Adaptation of existing interventions for self-assessment of risk was rejected. Use of the popular farm press and respected local resources were desired as avenues for safety education. Humor and stories were highly regarded. Interventions should be tailored for the target audience. These new insights into the risk perceptions of senior farmers and their families may result in more appropriate actions by health professionals, extension staff, social workers, vocational rehabilitation specialists, and others who work with farm populations.

Keywords. Family, Farm safety, Farmer's attitude, Health protection.

$\mathrm{F}$ armers represent one of the most aged occupational workforces in the U.S. (USDOL, 2013). The average age of the principal farm operator has increased roughly one year in each census cycle, from 50.3 in 1978 to 58.3 in 2012, and is expected to continue this upward trend into the next decade and beyond (USDA, 2007, 2014).

Agriculture is one of the nation's most hazardous industries and one of the few industries in which there is no customary retirement age. Senior farmers suffer a disproportionate number of injuries and the highest fatal injury rate of all age groups who farm. An examination by Myers et al. (2009) of the NIOSH Occupational Injury Surveillance of Production Agriculture for 2001 and 2004 revealed that farmers and farm workers age 55 and older averaged 26,873 lost-time injuries in each of those years, constituting an injury rate of 4.5 injuries per 100 workers per year. Senior farmers accounted for over half of all farming deaths between 1992 and 2004. These grim statistics underscore the importance of working with farmers to develop strategies for their safety, especially as they reach their later years of life.

Submitted for review in December 2014 as manuscript number JASH 11100; approved for publication by the Ergonomics, Safety, \& Health Community of ASABE in June 2015.

The authors are Deborah B. Reed, Distinguished Professor, and Deborah T. Claunch, Research Associate, College of Nursing, University of Kentucky, Lexington, Kentucky. Corresponding author: Deborah B. Reed, 553 CON Building, University of Kentucky, Lexington, KY 40536-0232; phone: 859-257-9636; e-mail: dbreed01@uky.edu.

Journal of Agricultural Safety and Health 
Complex and multidimensional physiological and psychological changes conspire to place senior farmers at a higher risk for injury and poorer outcomes than their younger counterparts. Decreased strength and flexibility, vision problems, hearing loss, onset of a chronic illness, and depression may limit a senior farmer's physical capabilities to farm safely (Cole and Donovan, 2008; Freeman et al., 2000). Literature supports that age-related health problems contribute to an elevated risk for injury. Senior farmers reporting chronic bronchitis/emphysema, arthritis, and sleeping problems have been found to have significantly higher odds of sustaining a farm-related injury (Heaton et al., 2010; Heaton et al., 2012; Marcum et al., 2011b). Older farmers with mobility problems are twice as likely to experience a farm work injury compared to those without mobility problems (Heaton et al., 2012). Functional cognitive declines associated with aging may decrease older adults' ability to comprehend and act in risky situations, such as farm work. Older adults generally adjust to the decline in mental resources in normal life by selecting tasks they can do well or by planning more thoroughly, but the pressures of farm work do not always allow these strategies to work in agriculture (McLaughlin and Sprufera, 2011).

Older adults typically consume more medications than middle-aged or younger adults to treat chronic conditions. A study of the association of medication use by older farmers and injury reported a strong relationship between the recent use of pain medication and subsequent injury (Voaklander et al., 2006). However, chronic health problems have only a minor impact on the number of hours worked on the farm (Marcum et al., 2011a). Older farmers carry workloads similar to their younger counterparts, working as much as 10 or 12 hours per day (Lizer and Petrea, 2007; Marcum et al., 2011a; Reed et al., 2012; Voaklander et al., 2010). Despite changes in their physical and mental abilities, senior farmers continue to work with a general attitude that the potential for injury is a normal part of their occupation (McLaughlin and Sprufera, 2011).

The computerized mechanization of farm equipment may also have an impact on injury risk for aging farm workers. While newer equipment comes with better safeguards and is designed to make work easier and faster, much of the equipment is also computerized. Senior farmers may not be familiar with the new technology. Older farmers are capable of learning new techniques, but learning may take longer, and the required time may not be available in peak work periods.

Farm work provides enjoyment and satisfaction, and cannot be disconnected from senior farmers' heritage and culture. Older farmers firmly link life satisfaction to their sense of accomplishment from their work (Maciuba et al., 2013; Reed et al., 2012), and they define good health as the ability to work (Reed et al., 2012). The desire and need to work align closely with the continuity theory of aging, which proposes that individuals age successfully when they continue their habits, preferences, lifestyles, and relationships from midlife into late life (Gullifer and Thompson, 2006). Experience, expertise, and wisdom may allow older adults to develop behavioral strategies that compensate for physical limitations (Cole and Donovan, 2008).

To effectively minimize the risks faced by older farmers and farm workers, Myers et al. (2009) emphasized that a thorough understanding of older workers' beliefs, values, and motivations is required, as well as the adoption of nontraditional prevention programs. While much attention has focused on the risks in agriculture, little attention has been paid to the continued work of the senior farmer, typically a person whose entire life has been involved in farm work. A "voice" for the senior farmer has not emerged. This exploratory, descriptive, qualitative study developed such a voice by examining older farmers' and their 
families' perspectives on farm work, associated risks, and methods employed to decrease those risks.

\section{Methods}

\section{Study Design}

The commitment to involve partners and stakeholders throughout the research process is central to NIOSH-funded research (Huy, 2010) and has long been recognized as essential to the effectiveness of prevention programs (Green and Kreuter, 1990; Seiz and Downey, 2001). Collaboration among the researchers, Cooperative Extension agents, and local farmers known to the researchers provided access to the farm community. Agents' and farmers' familiarity and rapport with the farm community added credibility to the study. Extension agents and local farmers promoted the study, identified potential participants, and provided private meeting rooms for focus groups. Personal interviews were conducted to include farmers who were unable to attend group discussions but wished to participate.

Standard focus group methodology was followed to collect the data (Krueger, 1998). Separate focus groups were held for the farmers and for their family members to allow more open discussion. Questions tailored to each group were based on the Health Belief Model, previous research, and a current literature review. Since its development in the 1950s, the Health Belief Model (HBM) has become the most widely used conceptual framework in health behavior research. The HBM contains six key concepts that predict why people will take action to prevent, screen for, or control illness conditions (Champion and Skinner, 2008). These concepts address individuals' perceptions of their chances of acquiring an injury or illness, the seriousness of the condition and its consequences, benefits of taking action to prevent the condition from occurring, tangible and psychological costs of the advised behavior, cues to actions, and confidence in their ability to take action.

Two members of the research team guided the group discussions. The primary facilitator used exploratory methods and a pre-established list of probing questions to assist interactions. Discussions included information about values and beliefs held by the senior farmers and their families as well as those identified in our conceptual framework. Three primary processes were used in the focus groups to capture data. Flipchart notes were taken during the meetings by a research team member and posted for group review. This process supported clarification and verification, served as a member check, and assisted in developing themes co-constructed with the participants (Anfara et al., 2002; Kvale, 1996). In addition, individual notes were taken by research team members relative to key points expressed and observations made. Finally, the discussions were audiotaped for subsequent review as a quality check to compare to the written notes, to ensure that no critical information was overlooked, and to place the data in context (Green and Thorogood, 2004). Personal participant interviews followed the same questions as those used in the focus groups. Content items were summarized and verified before each interview ended. Consistent with thematic content analysis, data collection and analysis was ongoing and integrated (Green and Thorogood, 2004). Such iterative analysis allowed us to identify and obtain insights on previously unexplored phenomena that emerged from the focus groups. Data analysis began during the sessions as the facilitator decided which responses to probe further and which to redirect. This was followed by engaging the participants in data verification and theme identification (Anfara et al., 2002; Kvale, 1996). After each session, research team mem- 
bers shared their observations and perceptions of the group members' interactions and confirmed major themes of the individual sessions. When all sessions and interviews were completed, the team revisited the preliminary analyses to identify overarching themes and search for congruence and divergence among the groups.

Participant demographic forms were used to gather insight into all participants' background in agriculture, self-perceived knowledge and risk perception about agriculture health and safety, as well as each participant's age, gender, marital status, and farm operation. All data collection procedures were approved by the university's Institutional Review Board prior to the initiation of the study.

\section{Findings and Results}

\section{Focus Groups and Participants}

The states for our study were selected based on geographic, cultural, and commodity diversity. Myers et al. (2009) reported that the highest numbers of deaths to older farmers occurred in the Midwest and South, while the highest fatality rate was in the Northeast. Three states (Kentucky, New York, and Nebraska) are in these geographic areas (fig. 1). These states also have higher proportions of older farmers and intense agricultural production.

To obtain potentially different perspectives on safety concerns, information was gathered from two distinct sets of focus groups. Reflective of the age cohort more at risk for work-related fatality, farmers age 55 and older comprised the first set of focus groups; the second set consisted of the farmers' families (e.g., spouses, adult children of older farmers). Five senior farmer focus groups, five personal interviews with senior farmers, and seven family member focus groups were conducted, achieving a total of 81 participants. Senior farmers $(n=43)$ were primarily male $(79 \%)$, while family members $(n=38)$ were equally split by gender. The full sample consisted of 53 males and 28 females. Data collection occurred from November 2010 through February 2013.

All participants had direct experience with safety issues confronting older farmers. Farmers ranged in age from 56 to $83($ mean $=69.6$; median $=70)($ table 1$)$. The average number of years in farming was 56.1 years. The group averaged 42 hours per week working on the farm, and $58 \%$ identified themselves as full-time farmers. Eighteen of the farmers

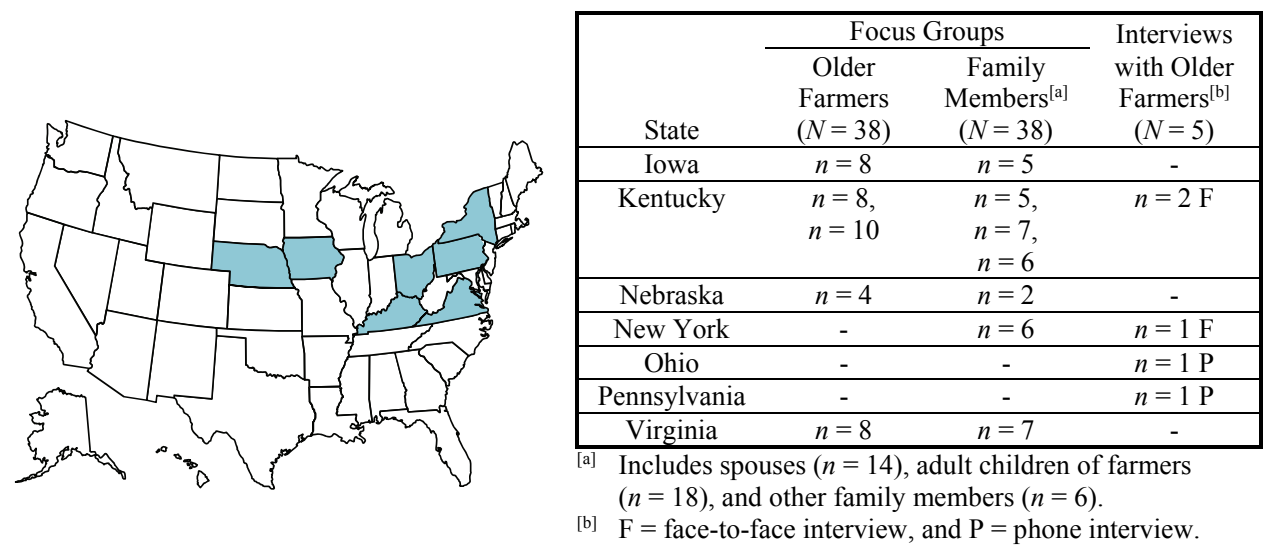

Figure 1. Data collection sites for older farmers and family members. 
Table 1. Senior farmer work status and average hours worked per week by age group.

\begin{tabular}{|c|c|c|c|c|c|c|}
\hline \multirow[b]{2}{*}{ Age Group } & \multirow{2}{*}{$\begin{array}{l}\text { Number } \\
\text { in Study }\end{array}$} & \multicolumn{4}{|c|}{ Self-Reported Farmer Status } & \multirow{2}{*}{$\begin{array}{c}\text { Average Hours } \\
\text { per Week }\end{array}$} \\
\hline & & Full-Time & Part-Time & Retired & No Answer & \\
\hline $56-59$ & 3 & 3 & & & & 67 \\
\hline $60-69$ & 18 & 14 & 3 & 1 & & 51 \\
\hline $70-79$ & 16 & 7 & 7 & 1 & 1 & 38 \\
\hline $80-83$ & 6 & 1 & 1 & 4 & & 12 \\
\hline Totals & 43 & 25 & 11 & 6 & 1 & 42 \\
\hline
\end{tabular}

reported working 50 or more hours per week. Even those who considered themselves "retired" reported working as much as 40 hours per week.

The majority of family member participants were either spouses or adult children or grandchildren of the senior farmers. All of them had performed farm work at some point in their lives, and over $80 \%$ of the family members were currently involved in farm work. Hours worked on the farm ranged from $1 / 2$ hour to 90 hours per week, with an average of 37.8 hours per week. Most of the participants considered themselves full-time or part-time farmers $(87 \%)$. Only two reported that they were "not a farmer," and three claimed they were retired. Thus, family members were well-versed in farming activities and safety concerns.

\section{Perceived Risks}

Farmers and family members were acutely aware of the dangers faced each day by senior farmers in the agricultural environment. However, from the self-rated risk analysis, only $52.4 \%$ of the farmers in this study considered themselves to be at high risk for injury. Family members perceived the farmer's risk for injury greater than did the farmers themselves (table 2). Discussions with the senior farmers disclosed that they consider the probability of a farm-related injury a normal part of their occupation, just like weather, disease, and other adverse conditions.

Farmers wanted to continue their work but acknowledged that physical and mental changes sometimes placed them at risk for injury. Slowed reflexes, limited range of motion, and fatigue led the list of health challenges. Although farmers recognized the need for good vision, balance, grip strength, alertness, and quick reaction time to perform farm tasks, they did not identify a lack or weakness in these areas as the hazard itself but rather cited external risk factors (table 3 ). Farmers also acknowledged that hurrying and multi-tasking could increase their risk for injury.

Table 2. Risk of farm injury to senior farmer as perceived by focus group participants.

\begin{tabular}{cccccc}
\hline & \multicolumn{2}{c}{ Senior Farmers' Self-Assessment } & & \multicolumn{2}{c}{ Family Members' Assessment } \\
\cline { 2 - 3 } \cline { 5 - 6 } Category & Number & Percentage & & Number & Percentage \\
\hline Very low & 5 & 11.9 & & 1 & 2.7 \\
Somewhat low & 15 & 35.7 & & 10 & 27.8 \\
Somewhat high & 20 & 47.6 & & 20 & 55.6 \\
Very high & 2 & 4.8 & & 5 & 13.9 \\
\hline Total responses $^{[\mathrm{a}]}$ & 42 & 100 & & 36 & 100 \\
\hline [a] & Based on actual responses (three missing) & &
\end{tabular}

[a] Based on actual responses (three missing).

Table 3. Perceived farm work hazards for older farmers. 
Family members had very different perspectives on older farmers' risks, noting that it was difficult to have conversations about declining work ability, and citing a respect for older farmers' decisions to remain active. Family members were most concerned that work restrictions would "break their [older farmer] spirits." One senior farmer reported that he had to tell his father that he could no longer drive the tractor. With tears in his eyes, the farmer stated, "It was the hardest conversation I ever had." The highest external risks cited by both farmers and family members were work involving tractors, livestock, machinery, and climbing.

While not specifically an aging issue, two disturbing shifts in the agricultural community were mentioned multiple times during focus group discussions that may have an impact on the workloads and work adjustments of aging farmers. One steadfast characteristic of the farm culture has been the willingness of farmers to help each other in times of need. However, the following quotation illustrates how the culture has changed: "It's not like it used to be. It used to provide social support. Now it's a dog-eat-dog world. No swapping labor. Too busy. Everybody's ready to sue over a little cut." This cultural change is responsible in part for the second change being experienced in farming. All participants agreed that even though farming is physically easier now than it was when they started out, the stress level is much greater.

Risk perception and actions to reduce risk were viewed differently by the senior farmers and their family members. The constructs of the HBM are used in figure 2 to illustrate these differences. Farmers were not as concerned about risk to self as about their actions injuring others, while family members focused on injury to the senior farmer. Stress, close calls, and actual injury are common points and may be useful as the foundations for communication and action

\begin{tabular}{|c|c|c|}
\hline Farmers & Health Belief Model & Family Members \\
\hline & 1. Individual perception of risk & High risk \\
\hline Injuring others; more stress & 2. Seriousness of consequences & Injury or death to farmer \\
\hline Less stress & 3. Benefits of taking action & Prevent injury; lower stress \\
\hline Close calls; injury & 4. Cues to action & Injury or multiple close calls \\
\hline $\begin{array}{l}\text { Confident: slow down, pay } \\
\text { attention, get help }\end{array}$ & 5. Confidence in ability to take action & $\begin{array}{l}\text { Low confidence; difficult to have } \\
\text { or start conversations }\end{array}$ \\
\hline $\begin{array}{l}\text { Decreased work; being } \\
\text { "set aside" }\end{array}$ & 6. Costs of taking action & $\begin{array}{l}\text { Resistance; disrespect; family } \\
\text { dysfunction }\end{array}$ \\
\hline & Common & \\
\hline & 3. Lower stress & \\
\hline & 4. Close calls; injuries & \\
\hline
\end{tabular}

Figure 2. Risk perception for older farmer injury applied to health belief model.

\section{Adaptations}

Adaptations reported by focus group participants to accommodate aging were grouped into four major themes. The specific adaptations within each theme are shown in table 4. The most often cited strategies used to reduce risk of injuries included slowing down, paying attention, and having someone else present while performing the task. Technological advances in equipment and administrative programming were met with mixed reviews. Some equipment used to offset health challenges (e.g., ATVs) also posed additional risk for injury. 
Table 4. Adaptations reported by focus group participants.

\begin{tabular}{ll}
\hline \multicolumn{1}{c}{ Theme } & \multicolumn{1}{c}{ Specific Adaptations Reported } \\
\hline Redistribution of work & Hire other people to perform certain tasks. \\
& Turn task over to someone else. \\
& Less walking and more talking and thinking. \\
& Find tasks for older farmer that aren't as risky. \\
& Avoid working alone. \\
\hline Restructure of the workday & Ease up on how much you do. \\
& Pace yourself. \\
& Take your time. \\
& Take a vacation. \\
& Take more breaks during the day. \\
& Plan ahead to decrease trips and steps (energy conservation). \\
\hline Re-evaluation of equipment use & Buy newer equipment. \\
& Cab tractors (helps allergies and has air conditioning). \\
& Use ATVs and Gators (utility vehicles) to get around. \\
& Use familiar equipment, not too technical or high speed. \\
& Keep equipment in better repair so others can use it. \\
\hline Realignment of farm operation (limited) & Change type of farm operation (e.g., from dairy to hay/beef cattle). \\
& Reduce size of farm operation (e.g., reduce number of livestock, \\
& rent out part of land). \\
\hline
\end{tabular}

Interestingly, two of the approaches described by the study participants did not yield positive results: (1) assigning the aging farmer an alternative task and (2) acquiring new equipment for the aging farmer to use. The shortcomings of both of these approaches occurred when the risks for injury of the alternate task or new equipment was overlooked or underestimated. While concerned family members felt they were protecting the senior farmers by finding them "safer" tasks or having them use newer and "safer" equipment, the senior farmers had a different viewpoint. Using equipment they were not familiar with or being asked to mow as an alternate "safe" task was perceived by the older farmers as a greater risk for injury. They were concerned about a tractor overturn, pushing a wrong button on the machine, and not knowing how to turn off a machine in an emergency. Family members had not considered these risks. This situation highlights the need for open communication as aging farmers and family members work together in making adjustments and decisions that are best for everyone.

\section{Intervention Strategies Identified by Participants}

Participants offered a number of suggestions that should underlie any intervention strategy. First, develop a relationship of trust with the farmer. Work with organizations that farmers respect and trust. Disseminate information through the written press that farmers are familiar with and find credible (e.g., farm publications, commodity group newsletters, Farm Bureau newsletters). Use humor, illustrations, and stories, which participants felt "soften the blow" of serious topics. Offer suggestions in a non-threatening way using thirdperson examples. Avoid using the word "stop" as it will have a negative impact. Design the intervention for all farmers. Begin conveying the messages earlier, before farmers reach advanced ages. Prepare the younger group for what lies ahead, and teach them to work smarter (the final thoughtful message). Emphasize that the farmer can still farm. 


\section{Discussion}

Numerous studies support that farmers have the appropriate knowledge to prevent injuries to themselves and others (McLaughlin and Mayhorn, 2011). However, knowledge alone is not effective in reducing the hazard exposure or risk for injury. Cole (2000) stressed that unless knowledge is supported by attitudes that help individuals perceive that the knowledge relates to their daily activities, behavior is unlikely to change, an idea that is fully supported by the Health Belief Model (Champion and Skinner, 2008). Behavior, therefore, is influenced by a combination of knowledge and attitudes about that knowledge. Based on this premise, to influence farmers' behavior, we must provide interventions that address the farmers' attitudes toward safety. The farmers in this study perceived the probability of a farm-related injury to themselves as a normal part of their occupation. McLaughlin and Sprufera (2011) reported similar findings. A common theme heard from our study participants was that the fear of hurting someone else is of greater concern to them than sustaining a personal injury.

Other studies have suggested that farmers assess risk by comparing themselves to other farmers and other situations (Cole, 2002) or by creating unique perceptions about what has to be done for them to stay safe (Seiz and Downey, 2001). In an agricultural setting, farmers watch what other farmers are doing, whether related to new production methods or with regard to safety and health, and create what they consider to be the social norm. This perception influences how they approach work and safety on their own farms. Colemont and Van den Broucke (2006) noted that farmers may practice unsafe or careless behavior in order to comply with what they perceive to be the norm in farming. Cole (2002) noted that attitudes are learned primarily through models of other people's behavior. This concept was confirmed in our focus groups, as the farmers often conversed about local trends, actions, and advice regarding agricultural activities. Thus, an effective intervention needs to incorporate a safety strategy that farmers will embrace as the "social norm" within their community.

The conflicting views about risk of injury between senior farmers and their family members illuminate the need to further explore the roles of family dynamics and communication. Senior farmers in this study listed the primary external causes of injury. This risk identification is congruent with the leading causes of injury and death in this age group (Myers et al., 2009). Family members were more likely to list the farmer's declining health. An exception to this was the issue of stress. Physical health conditions can be controlled to some extent so work can continue; however, worry and stress may cloud decision making and create distractions. This, in turn, leads to an increased risk for injury. Other studies have substantiated the relationship between stress and injury (Lizer and Petrea, 2008; Simpson et al., 2004). Family members noted stress in initiating discussions about risky behavior with the senior farmers. Sometimes this led to discord and hurt feelings that permeated multiple generations. Guidance on how to approach critical conversations may help alleviate stress, promote healthier family relationships, and lead to risk reduction.

The farmers and their family members agreed that close calls or actual injuries would prompt them to action. These incidents may be prime times for professionals to counsel the farm family on risk reduction and provide support for action. Tactful engagement in these delicate conversations led by trusted colleagues may provide the catalyst to reduce risks.

Participants in this study offered candid suggestions for future intervention paths and messages. They indicated that they intend to keep working but would welcome strategies 
that are based in their culture and on their expectations. Such interventions should be developed in tandem with farm groups for maximum effectiveness (Green and Kreuter, 1990; Seiz and Downey, 2001).

An earlier study on sustained work indicators of older farmers suggested that perhaps the most important intervention is to acknowledge the importance of work to older farmers (Maciuba et al., 2013; Reed et al., 2012). Farm work provides a sense of accomplishment, satisfaction, and enjoyment that is therapeutic to farmers. The challenge is to develop work strategies that are not perceived as a means of denying the farmers the work they want to do.

\section{Conclusions and Implications}

The results of this exploratory study support prior evidence that farmers are aware of the risks and hazards of farm work as they age. This study confirmed that farmers are independent and prefer to be in control of their circumstances. Interventions designed to protect senior farmers can serve a dual purpose by also alerting younger farmers to the issues they will ultimately face and getting them started on a more proactive approach to health and safety. It is imperative that future interventions be grounded not only in theory but also in the reality of older farmers and their families. Because of the cultural context of farm life, work modification counseling may be more beneficial for aging farmers than abstinence from work. This new insight may result in increased attention and more appropriate actions by health professionals, Extension staff, social workers, vocational rehabilitation specialists, and others who work with farm populations.

\section{Acknowledgements}

The authors wish to thank the farm families and safety professionals who contributed to this study. We thank the Cooperative Extension Agents who facilitated recruitment and provided meeting space. This study was funded by the National Institute for Occupational Safety and Health under Grant No. R21OH009494. The findings presented do not imply endorsement by the funding agency.

\section{References}

Anfara, V. A., Brown, K. M., \& Mangione, T. L. (2002). Qualitative analysis on stage: Making the research process more public. Educ. Researcher, 31(17), 28-38. http://dx.doi.org/10.3102/0013189X031007028.

Champion, V. L., \& Skinner, C. S. (2008). The health belief model. In K. Glanz, B. K. Rimer, \& K. Viswanath (Eds.), Health Behavior and Health Education: Theory, Research, and Practice (pp. 45-65). San Francisco, Cal.: Jossey-Bass.

Cole, H. P. (2000). Knowledge is not enough. J. Agric. Saf. Health, 6(4), 245-247.

Cole, H. P. (2002). Cognitive-behavioral approaches to farm community safety education: A conceptual analysis. J. Agric. Saf. Health, 8(2), 145-159. http://dx.doi.org/10.13031/2013.8428.

Cole, H. P., \& Donovan, T. A. (2008). Older farmers' prevalence, capital, health, age-related limitations, and adaptations. J. Agromed., 13(2), 81-94. http://dx.doi.org/10.1080/10599240802125680.

Colemont, A., \& Van den Broucke, S. (2006). Psychological determinants of behaviors leading to occupational injuries and diseases in agriculture: A literature overview. J. Agric. Saf. Health, 12(3), 227-238. http://dx.doi.org/10.13031/2013.21230.

Freeman, S., Schwab, C., \& Miller, L. (2000). Keep active farmers safe in later life. Ames, Iowa: Iowa State University Extension.

Green, J., \& Thorogood, N. (2004). Analysing qualitative data. In Qualitative Methods for Health 
Research (1st ed., pp. 173-200). London, U.K.: Sage Publications.

Green, L. W., \& Kreuter, M. W. (1990). Health promotion as a public health strategy for the 1990s. Ann. Rev. Public Health, 11, 319-334. http://dx.doi.org/10.1146/annurev.pu.11.050190.001535.

Gullifer, J., \& Thompson, A. P. (2006). Subjective realities of older male farmers: Self-perceptions of aging and work. Rural Soc., 16(1), 80-97. http://dx.doi.org/10.5172/rsj.351.16.1.80.

Heaton, K., Azuero, A., \& Reed, D. (2010). Obstructive sleep apnea indicators and injury in older farmers. J. Agromed., 15(2), 148-156. http://dx.doi.org/10.1080/10599241003636020.

Heaton, K., Azuero, A., Phillips, J. A., Pickens, H., \& Reed, D. (2012). The effects of arthritis, mobility, and farm task on injury among older farmers. Nursing Res. Rev., 2, 9-16. http://dx.doi.org/10.2147/nrr.s28122.

Huy, J. (2010). Involving farmers in preventing work-related injuries and illnesses: The NIOSH research-to-practice initiative. J. Agromed., 15(2), 98-100. http://dx.doi.org/10.1080/10599241003627128.

Krueger, R. A. (1998). Moderating Focus Groups. Thousand Oaks, Cal.: Sage Publications.

Kvale, S. (1996). Interviews: An Introduction to Qualitative Research Interviewing. Thousand Oaks, Cal.: Sage Publications.

Lizer, S. K., and Petrea, R. E. (2007). Health and safety needs of older farmers: Part I. Work habits and health status. American Assoc. Occup. Health Nurses J., 55(12), 485-491.

Lizer, S. K., and Petrea, R. E. (2008). Health and safety needs of older farmers: Part II. Agricultural injuries. American Assoc. Occup. Health Nurses J., 56(1), 9-14. http://dx.doi.org/10.3928/08910162-20080101-05.

Maciuba, S. A., Westneat, S. C., \& Reed, D. B. (2013). Active coping, personal satisfaction, and attachment to land in older African-American farmers. Issues Mental Health Nursing, 34(5), 335343. http://dx.doi.org/10.3109/01612840.2012.753560.

Marcum, J. L., Browning, S. R., Reed, D. B., \& Charnigo, R. J. (2011a). Determinants of work hours among a cohort of male and female farmers 50 years and older in Kentucky and South Carolina (2002-2005). J. Agromed., 16(3), 163-173. http://dx.doi.org/10.1080/1059924X.2011.581529.

Marcum, J. L., Browning, S. R., Reed, D. B., \& Charnigo, R. J. (2011b). Farmwork-related injury among farmers 50 years of age and older in Kentucky and South Carolina: A cohort study, 20022005. J. Agric. Saf. Health, 17(3), 259-273. http://dx.doi.org/10.13031/2013.38186.

McLaughlin, A. C., \& Mayhorn, C. B. (2011). Avoiding harm on the farm: Human factors. Gerontechnology, 10(1), 26-37. http://dx.doi.org/10.4017/gt.2011.10.01.002.00.

McLaughlin, A. C., \& Sprufera, J. F. (2011). Aging farmers are at high risk for injuries and fatalities: How human-factors research and application can help. North Carolina Med. J., 72(6), 481-483.

Myers, J. R., Layne, L. A., \& Marsh, S. M. (2009). Injuries and fatalities to U.S. farmers and farm workers 55 years and older. American J. Ind. Med., 42(3), 185-194. http://dx.doi.org/10.1002/ajim.20661.

Reed, D. B., Rayens, M. K., Conley, C. K., Westneat, S., \& Adkins, S. M. (2012). Farm elders define health as the ability to work. Workplace Health Safety, 60(8), 345-351. http://dx.doi.org/10.3928/21650799-20120716-49.

Seiz, R. C., \& Downey, E. P. (2001). What farm families tell us that can be useful in educating for health and safety. J. Extension, 39(6), 6FEA5.

Simpson, K., Sebastian, R., Arbuckle, T. E., Bancej, C., \& Pickett, W. (2004). Stress on the farm and its association with injury. J. Agric. Saf. Health, 10(3), 141. http://dx.doi.org/10.13031/2013.16471.

USDA. (2007). 2007 Census of Agriculture: Farmers by age. Washington, D.C.: USDA National Agricultural Statistics Service. Retrieved from www.agcensus.usda.gov/Publications/2007/Online Highlights/Fact_Sheets/Demographics/farmer_age.pdf.

USDA. (2014). 2012 Census of Agriculture. Preliminary report highlights: U.S. farms and farmers. Washington, D.C.: USDA National Agricultural Statistics Service. Retrieved from www.agcensus.usda.gov/Publications/2012/Preliminary_Report/Highlights.pdf.

USDOL. (2013). Labor force statistics from the current population survey: Employed persons by 
detailed occupation and age, 2013 annual averages. Washington, D.C.: U.S. Department of Labor, Bureau of Labor Statistics. Retrieved from www.bls.gov/cps/occupation_age.htm.

Voaklander, D. C., Kelly, K. D., Rowe, B. H., Schopflocher, D. P., Svenson, L., Yiannakoulias, N., \& Pickett, W. (2006). Pain, medication, and injury in older farmers. American J. Ind. Med., 49(5), 374-382. http://dx.doi.org/10.1002/ajim.20292.

Voaklander, D. C., Dosman, J. A., Hagel, L. M., Warsh, J., \& Pickett, W. (2010). Farm work exposure of older male farmers in Saskatchewan. American J. Ind. Med., 53(7), 706-715.

http://dx.doi.org/10.1002/ajim.20811. 